NBER WORKING PAPER SERIES

\title{
INTERGENERATIONAL LONG TERM EFFECTS OF PRESCHOOL - STRUCTURAL ESTIMATES FROM A DISCRETE DYNAMIC PROGRAMMING MODEL
}

\author{
James J. Heckman \\ Lakshmi K. Raut \\ Working Paper 19077 \\ http://www.nber.org/papers/w19077
NATIONAL BUREAU OF ECONOMIC RESEARCH
1050 Massachusetts Avenue
Cambridge, MA 02138 \\ May 2013
}

\begin{abstract}
We would like to thank the anonymous Associate Editor and two referees of the Journal of Econometrics for many valuable comments. An earlier draft was presented at the Centre for Development Studies, Indian Statistical Institute, Indira Gandhi Institute of Development Research, Nanyang Technological University, Periyar University, Singapore National University, University of Nevada at Las Vegas, Tokyo University, University of Southern California, and the Western Economic Association Meeting, 2003. Comments of the participants of these workshops, especially of Juan Pantano as a discussant of the Western Economic Association conference and comments from Han A.T. Raut and T.N. Srinivasan are gratefully acknowledged. This research was supported in part by the American Bar Foundation, the Pritzker Children's Initiative, the Buffett Early Childhood Fund, NICHD R37 HD065072, R01 HD054702, the Human Capital and Economic Opportunity Global Working Group - an initiative of the Becker Friedman Institute for Research in Economics - funded by the Institute for New Economic Thinking (INET), and an anonymous funder. Raut is an Economist at the Social Security Administration (SSA). This paper was prepared prior to his joining SSA. The analysis and conclusions expressed are those of the authors and not necessarily those of SSA, nor of the funders or commentators mentioned here, nor of the National Bureau of Economic Research.
\end{abstract}

NBER working papers are circulated for discussion and comment purposes. They have not been peerreviewed or been subject to the review by the NBER Board of Directors that accompanies official NBER publications.

(C) 2013 by James J. Heckman and Lakshmi K. Raut. All rights reserved. Short sections of text, not to exceed two paragraphs, may be quoted without explicit permission provided that full credit, including (C) notice, is given to the source. 
Intergenerational Long Term Effects of Preschool - Structural Estimates from a Discrete Dynamic Programming Model

James J. Heckman and Lakshmi K. Raut

NBER Working Paper No. 19077

May 2013

JEL No. I21,J24,J62,O15

\begin{abstract}
$\underline{\text { ABSTRACT }}$
This paper formulates a structural dynamic programming model of preschool investment choices of altruistic parents and then empirically estimates the structural parameters of the model using the NLSY79 data. The paper finds that preschool investment significantly boosts cognitive and non-cognitive skills, which enhance earnings and school outcomes. It also finds that a standard Mincer earnings function, by omitting measures of non-cognitive skills on the right hand side, overestimates the rate of return to schooling. From the estimated equilibrium Markov process, the paper studies the nature of within generation earnings distribution and intergenerational earnings and schooling mobility. The paper finds that a tax financed free preschool program for the children of poor socioeconomic status generates positive net gains to the society in terms of average earnings and higher intergenerational earnings and schooling mobility.
\end{abstract}

James J. Heckman

Department of Economics

The University of Chicago

1126 E. 59th Street

Chicago, IL 60637

and University College Dublin and IZA

and also NBER

jjh@uchicago.edu

Lakshmi K. Raut

Social Security Administration

400 Virginia Avenue SW, Suite 300

Washington DC 20024

Lakshmi.Raut@ssa.gov 


\section{Introduction}

This paper formulates and estimates an altruistic model of parental preschool investment decisions.

In our model preschool investments affect the cognitive and non-cognitive skills of the children and hence their lifetime permanent earnings and school outcomes. Optimal choices by parents determine the equilibrium controlled Markov process, characterizing the equilibrium dynamics of earnings distributions within each generation, and the schooling and earnings mobility across generations. We also examine the effect of a social policy that provides free preschool to children of low socioeconomic status (SES) financed by taxing all parents in the population, on the distribution of earnings within generation and on intergenerational earnings and schooling mobility. We use the NLSY79 (National Longitudinal Survey of Youth, 1979) and the NLSY79 Children and Young Adults data containing information on a nationally representative sample of parent-child pairs of the US population. This paper extends Raut $(2003)$ by incorporating unobserved heterogeneity and estimating the structural parameters. The paper utilizes the Rust (1987) nested fixed point maximum likelihood estimation procedure.

Two important building blocks of our model are: (1) The stochastic production processes of the cognitive and non-cognitive skills with early childhood investment as one of the inputs; (2) An augmented Mincer earnings function that adds non-cognitive skills to the standard Mincer earnings function. We estimate these relationships. We provide an estimate of the extent to which the rate of return to schooling in the standard Mincer earnings function is inflated because the schooling level in the standard Mincer earnings function embodies the effect of the omitted non-cognitive 
skills variables.

In the past three decades, the income gap between the rich and the poor and the wage gap between the college educated and the non-college educated workers in the US have been widening. Equalizing education is advocated as the main policy in the US to reduce poverty and income disparities. Many are, however, highly skeptical about a positive answer to the basic question: "Can we conquer poverty through school?"

There are many reasons for this skepticism. In the US, education up to high school level is virtually free. Yet many children of poor SES do not complete high school and many of them perform poorly in schools. Gaps in test score between the rich and poor children are substantial and unequal schooling does little to widen this gap (Carneiro and Heckman, 2003; Heckman, 2008). In spite of its positive effects on test scores and earnings, the effects of improved school quality on school drop out rates is marginal.

A growing consensus reached among educators, among media writers (see for instance Traub, 20(0)), among researchers in economics (see for instance Carneiro and Heckman, 20()3; Cunha et al, 2006; Heckman, 20(0), 2008) find that children of poor SES are not prepared for college because they were not prepared for school to begin with. The most effective intervention for the children of poor SES should be directed at the preschool stage so that these children are prepared for school and college. The question is then, does preschool experience have long-term positive effects on school performance and labor market success? This is the main issue that we address in this paper and corroborates the evidence in Cunha and Heckman (2007, 20()9); Heckman et al. $(2010 \mathrm{a}, \mathrm{b})$ that early intervention is effective. 
There are two types of quantitative studies on this issue. One set of studies use data on high cost high quality pilot preschool programs such as the High Scope/Perry Preschool Program (see Heckman et al., 2010),b) and the North Carolina Abecedarian Study (Campbell et al., 2012). These studies find a substantial lasting effect of these programs on school performance and labor market outcomes. The participants in these programs are not representative of the US population.

The other set of studies use data on the Head Start preschool program which is funded by the Federal government. It is available to the children whose parents earn incomes below poverty line. Not all eligible children are, however, covered by the program. The quality of the program is very poor compared to the enriched pilot programs or most private preschool programs. Some studies find that the Head Start Preschool Program has no long-term effect on children's cognitive achievements and school performance, especially for black children. Currie and Thomas (1995) carry out a careful econometric investigation and conclude that the benefits disappear for black children because most of the Head Start black children attend low quality public schools. But after controlling for the school quality, they find significant positive effects of Head Start Preschool Program. See the recent study by Deming (20()9).

These studies are not based on nationally representative samples of children. Most studies examine only the effect on school performance such as grade retention and high school and college graduation rates, and do not model parental choice of investing in their children's preschool. In this paper, we formulate a model of parental investment in preschool that is guided by economic incentives. We show that the preschool experience benefits children in acquiring many useful cognitive and non-cognitive skills, especially for the children of poor SES who live in poor HOME 
environments - a measure of family investment. We also show the importance of non-cognitive skills in improving school performance and life-time earnings of children, after controlling for their education level, innate ability, and family background. Almlund et al. (2011); Duckworth, Almlund, Kautz, and Heckman (Duckworth et al.); Heckman and Kautz (2012) summarize the literature on the effects of noncogntive traits on earnings.

The rest of the paper is organized as follows. Section $\square$ describes the intergenerational altruism model of parental preschool investment within a structural dynamic programming framework. Section [3] describes the estimation algorithm that we use. Section 1 provides the empirical specification of the production processes of cognitive and non-cognitive skills and reports the parameter estimates. Section $[$ conducts a policy analysis. Section 6 concludes.

\section{The Basic Framework}

In this section we formulate an econometrically implementable model of preschool investment of altruistic parents in a structural dynamic programming framework. We describe how we compute the long-run equilibrium distributions of earnings and schooling within generation. A transition probability matrix of earnings or schooling levels provides information about the degree of intergenerational earnings or schooling mobility or if there is intergenerational poverty cycle. We explain how we compute the mobility index from a transition matrix and how we compute the long-run equilibrium tax rate to finance the free preschool to the children of poor SES and its netgain or loss to the society in terms of welfare gains and loses of various groups, and in terms of 
change in the per capita disposable (i.e., after tax) earnings in the long-run equilibrium.

We assume a parthenogenetic mode of biological reproduction in our model and with due respect to both genders, all individuals are male gender. Parents of period $t$ will be referred to as generation $t$. Each parent has one child. After parents of generation $t$ die at the end of period $t$, their children become the parents of generation $t+1$ and make decisions for their children and the economy goes on in this recursive manner for ever.

In each period, parents are characterized by a vector of observed characteristics $x$, and a vector of unobserved characteristics $\varepsilon$, which are described in detail below. We summarize these traits by a vector $z=(x, \varepsilon)$. When we need to be specific about his generation $t$ or period $t$, we write him as $z_{t}=\left(x_{t}, \varepsilon_{t}\right)$. We assume that each component of $x$ takes finite number of values, thus $x$ will be from a finite set $\mathcal{X}$ with $m$ elements. We assume that the set $\mathcal{X}$ is ordered with elements $x_{1}, \ldots ., x_{m}$ in it. For a parent-child pair, if $v$ is a variable that refers to the parent, we use $v^{\prime}$ to denote the corresponding variable for his child.

An individual's life time consists of several stages during which important life-cycle events relevant to learning and earning occur. A parent invest in his child's preschool activities during ages [0-5), which help develop his child's school readiness, and various cognitive and non-cognitive skills. Denote by $a$ the preschool investment choice of a parent. At the end of the preschool period, the child acquires levels of innate ability or cognitive skill $\tau$, social skill $\sigma$, motivational skill $\mu$, self-esteem skill $\eta$, and internal self-control skill $\phi$.

During ages [5-17), the child goes to school. The school performance at this stage depends on his level of $\tau, \sigma, \mu, \eta$, and $\phi$ that the child has acquired during the previous stage. It also depends 
on the quality of the school that he attends ${ }^{\boxplus}$, the quality of the neighborhood, and the parental home inputs such as how many hours of time the parent spend with the child to do his homework, how many hours the child watches TV and the type of programs he watches, and how stable and stimulating the relationships among the family members are. Many of these are choice variables for the parent. We do not have adequate information about these factors in our dataset, so we do not analyze them. ${ }^{\text {D }}$

During ages [17-26), the child decides the number of years of schooling to complete, which depends on his parent's family background, his own cognitive and non-cognitive abilities $\tau, \sigma, \mu$, $\eta$, and $\phi$, and some random shocks $\varepsilon_{s}$. We take this decision to be exogenously given, and denote its dependence on these factors by the function $s=s\left(\tau, \sigma, \mu, \eta, \phi, s, \varepsilon_{s}\right)$.

During ages [26-], he works, forms his family, procreate one child and chooses a preschool investment plan for his child. In section 4.1, we describe in detail the components of the observed characteristics vector $x=(\tau, \sigma, \mu, \eta, \phi, s)$. In this section, we sequentially define below the components of the vector of his unobservable characteristics $\varepsilon$.

The production sector of the economy uses a linear production function with labor in efficiency unit as the only input. An individual with observed cognitive and non-cognitive skills $x=(\tau, \sigma, \mu, \eta, \phi, s)$ is assumed to be equivalent to the unit of labor in efficiency unit $w(x)+\varepsilon_{1}$, where $\varepsilon_{1}$ given $x$ is a mean-zero random productivity shock or it can be interpreted as mean-zero

\footnotetext{
${ }^{1}$ Even differences in school qualities and parental choices of school quality in an altruistic dynamic programming framework can limit social mobility and lead to the intergenerational poverty trap, see Nishimura and Raut (20)7) for such a model.

${ }^{2}$ However, see the studies by Cunha et al. (2010) and Cunha and Heckman (2008), as well as Mohanty and Raut (2009) and Boca et al. (2013).
} 
measurement error. The individual and the firm observe $\varepsilon_{1}$ but it is unobserved by others. Let $\pi(x)$ be the probability density function on the set of observable characteristics $\mathcal{X}$ in that period and $g_{1}\left(d \varepsilon_{1}\right)$ be the probability density ${ }^{[]}$of the random shock $\varepsilon_{1}$ given $x$. The aggregate output, which turns out to be also the per capita income or the average income of the economy in any period is

$$
Y=\sum_{x \in \mathcal{X}}\left[\int w(x)+\varepsilon_{1}\right] \pi(x) g_{1}\left(d \varepsilon_{1}\right)=\sum_{x \in \mathcal{X}} w(x) \pi(x)^{\mathbb{\theta}}
$$

An individual with skills $x$ and productivity shock $\varepsilon_{1}$ ends up with the marginal product $w=$ $w(x)+\varepsilon_{1}$ in the labor market. This $w$ is his annualized permanent earnings out of which he chooses a preschool investment plan $a$ for his child. The annual cost of his investment plan $a$ is $\tilde{\theta}(a) \equiv \theta(a)+\varepsilon_{2}(a)$, where $\theta$ is a constant for all parents and $\varepsilon_{2}$ is an unobserved parent specific variation in the cost, assumed to have zero mean. The rest of his earnings makes up his annualized permanent consumption $c \equiv w-\tilde{\theta}(a)=w(x)-\theta(a)+\varepsilon(a)$, where $\varepsilon(a) \equiv \varepsilon_{1}-\varepsilon_{2}(a)$. We assume that the parents with observed characteristics $x$ have a finite number of feasible preschool choices which is represented by the ordered set $A(x)$. The utility or reward of a parent $(x, \varepsilon)$ from a preschool investment choice $a \in A(x)$ has the form $u(x, \varepsilon, a)=u(x, a)+\varepsilon(a)$ where $u(x, a) \equiv w(x)-\theta(a)$. In the rest of the exposition we assume general form for $u(x, a)$.

Finally, we define the components of the unobserved heterogeneity vector $\varepsilon$ of an individual of

\footnotetext{
${ }^{3}$ We use the convention of denoting the probability density $g$ of a continuous random variable $\varepsilon$ by the notation $g(d \varepsilon)$ and for a discrete random variable $x$ by $g(x)$ and for their joint density as $g(x, d \varepsilon)$.

${ }^{4}$ In a similar theoretical model, Raut (1995) includes an external total factor productivity multiplier that increases with an increase in the number of skilled workers in the economy. The paper showed that policies that lead to higher social mobility also leads to higher economic growth.
} 
observed characteristics $x$ as $\varepsilon=(\varepsilon(a), a \in A(x))$, where $\varepsilon(a)$ is defined above. Denote by $\mathcal{E}$ the set of all possible $\varepsilon$.

In any period for a parent $z=(x, \varepsilon)$ with a preschool investment choice $a$, his child's vector of cognitive and non-cognitive skills and unobserved heterogeneity shocks, i.e., the vector $z^{\prime}=$ $\left(x^{\prime}, \varepsilon^{\prime}\right)$, is produced stochastically, which is characterized by the transition probability density function $p\left(x^{\prime}, d \varepsilon^{\prime} \mid x, \varepsilon, a\right)$.

The preschool investment choice problem of the parent $(x \varepsilon)$ is given by the following Bellman equation:

$$
V(x, \varepsilon)=\max _{a \in A(x)} u(x, \varepsilon, a)+\beta \sum_{x^{\prime} \in X} \int V\left(x^{\prime}, \varepsilon^{\prime}\right) p\left(x^{\prime}, d \varepsilon^{\prime} \mid x, \varepsilon, a\right)
$$

where $V(x, \varepsilon)$ is his maximized welfare, i.e. the value function, $u($.$) is the utility he derives from$ his own consumption; the utility he derives from his child's welfare is the expected maximized welfare $V\left(x^{\prime}, \varepsilon^{\prime}\right)$ of the child, discounted by $\beta$, the degree of parental altruism towards the child. His influence over his child's wellbeing is through his preschool investment choice $a$, which affects his child's cognitive and non-cognitive skill formations as reflected in the transition probability density function $p\left(x^{\prime}, d \varepsilon^{\prime} \mid x, \varepsilon, a\right)$. Under general regularity conditions on $u(),. p\left(x^{\prime}, d \varepsilon^{\prime} \mid x, \varepsilon, a\right)$ and $\beta$, the measurable value function $V(x, \varepsilon)$ and measurable optimal decision rule $a(x, \varepsilon)$ exist (see, for instance, Bhattacharya and Majumdar (1989), Theorem 3.2).

An equilibrium in our model is a controlled Markov process with a given initial distribution of parent population $\mu_{0}(x, d \varepsilon)$ on $\mathcal{X} \times \mathcal{E}$ in period $t=0$, a family of optimal preschool investment decisions $a(x, \varepsilon), x \in X$ and $\varepsilon \in \mathcal{E}$ and the stationary transition probability density function 
$p\left(x^{\prime}, d \varepsilon^{\prime} \mid x, \varepsilon, a(x, \varepsilon)\right)$. These variables determine the equilibrium dynamics of the earnings distribution and the degree of intergenerational earnings and college mobilities, and how these are affected by a public policy as described below.

This level of generality makes the estimation of the model computationally intractable. We are more interested in studying the equilibrium dynamics over the observable states $\mathcal{X}$. Since $\mathcal{X}$ is finite the equilibrium dynamics over it is a Markov chain, determined by the initial distribution $\pi_{0}$ of population over $\mathcal{X}$, and the transition probability matrix $\Pi=\left[\Pi\left(x, x^{\prime}\right)\right]_{x, x^{\prime} \in \mathcal{X}}$. We derive $\pi_{0}$, and $\Pi$ from the above equilibrium controlled Markov process, $\mu_{0}, a$, and $p(. \mid$.$) . A stationary or$ long-run equilibrium in this reduced set-up is a probability density function $\pi$ over the observable states $\mathcal{X}$ such that $\pi=\pi \Pi$, i.e., an invariant distribution $\pi$ of the transition probability matrix $\Pi$. Given $\pi_{0}$ and $\Pi$, we can examine how the population distribution $\pi_{t}$ on $\mathcal{X}$ changes over time $t$. The structure of $\Pi$ can tell us if there exists a unique invariant distribution, and whether the equilibrium population distribution $\pi_{t}$ over time $t$ converges to the invariant distribution as $t$ becomes large. A sufficient condition for both is that $\Pi\left(x, x^{\prime}\right)>0$ for all $x, x^{\prime} \in \mathcal{X}$. If the equilibrium transition matrix of $\Pi$ exhibits a block-diagonal structure (after reordering of the states in $\mathcal{X}$ if necessary), then the economy would exhibit an intergenerational poverty cycle. However, our empirical estimates of $\Pi$ have all elements strictly positive. Hence we do not have intergenerational poverty cycles. The unique invariant distribution is the long-run equilibrium distribution that the economy will converge to starting at any initial distribution $\pi_{0}$.

A number of mobility measures have been proposed in the literature for the Markov process determined by a transition matrix. Sommers and Conlisk (1979) argues that $1-\lambda_{\max }$ is the most 
appropriate measure of social mobility, where $\lambda_{\max }$ is the second highest positive eigenvalue of the transition probability matrix (it is well-known that the highest positive eigenvalue of a transition probability matrix is always 1 ). We use this measure for earnings or college mobility, and use the Gini coefficient of average earnings over the observable states (i.e., the Gini coefficients of earnings distribution $(w(x), \pi(x), x \in \mathcal{X})$ to compare the effects of our public preschool policy.

Public preschool policy: We consider the effect of introducing a publicly provided free preschool to children of poor SES financed by taxing all parents. In any period, we define parents of observable state $x$ to fall in the poor SES category if $w(x) \leq 0.7 \bar{w}$ where the average or per capita earnings $\bar{w}=\sum w(x) \pi(x)$. Denote by $\mathcal{X}_{p}$ the set of observable characteristics of the parents of poor SES. The equilibrium tax rate $\tau$ is then given by $\tau=\theta \sum_{x \in \mathcal{X}_{p}} w(x) \pi(x) / \sum_{x \in \mathcal{X}} w(x) \pi(x)$. Once such a policy is introduced, a new set of optimal preschool investment decision rules and a new transition matrix will emerge, affecting the invariant distribution, degree of earnings and schooling inequalities within generation, and the degree of social and college mobilities between generations. We estimate these effects empirically.

\subsection{The Econometric Methodology}

We follow the Rust (1987, 1994) approach to estimation of dynamic discrete choice model. He introduced the following three assumptions to convert the choice problem in Equation (D) into a random utility model.

Assumption 1 For $u(x, \varepsilon, a)=u(x, a)+\varepsilon(a)$, the support of $\varepsilon(a)$ is the real line for all $a \in$ 
$A(x)$.

Assumption 2 The transition probability $p\left(x^{\prime}, d \varepsilon^{\prime} \mid x, \varepsilon, a\right)=f\left(x^{\prime} \mid x, a\right) g\left(d \varepsilon^{\prime} \mid x^{\prime}\right)$ for some twice continuously differentiable density function $g$ with finite first moment.

Assumption 3 The components of $\varepsilon$ are independently and identically distributed as extreme value distribution with location parameter 0 and scale parameter 1.

Let $\Omega(x, a)=\{\varepsilon \mid$ for individual $(x, \varepsilon)$, the choice $a$ is optimal $\}$. The conditional choice probabilities are defined as $P(a \mid x)=\int_{\Omega(x, a)} g(d \varepsilon \mid x)$. Denote the vector of conditional choice probabilities by $\mathcal{P}=\{P(a \mid x), a \in A(x), x \in \mathcal{X}\}$. Let $\Delta$ be the set of all possible vectors of conditional probabilities. Under the above assumptions, it is easy to see that the transition probability matrix $\Pi$ and the average welfare of individuals in observable characteristics group can be computed with the conditional choice probabilities only. Furthermore, the computation of the conditional choice probabilities becomes a simpler iterative fixed point computation of a map $\Psi$ on the finite dimensional compact set $\Delta$ as given below.

$$
\Pi\left(x, x^{\prime}\right)=\sum_{a \in A(x)} f\left(x^{\prime} \mid x, a\right) P(a \mid x)
$$

The average welfare of the group with observable state $x$ has the form

$$
v(x) \equiv \int V(x, \varepsilon) g(d \varepsilon \mid x)=\sum_{a \in A(x)} P(a \mid x)[u(x, a)+e(x, a)+\beta F(x, a) \cdot v]
$$


where $v=\left[v\left(x_{1}\right), \ldots, v\left(x_{m}\right)\right]^{\prime}$ is a column vector, $e(x, a)=\int_{\Omega(x, a)} \varepsilon g(d \varepsilon)$, and $F(x, a)=$ $\left[f\left(x_{1} \mid x, a\right), \ldots, f\left(x_{m} \mid x, a\right)\right]$, a $m$ dimensional row vector.

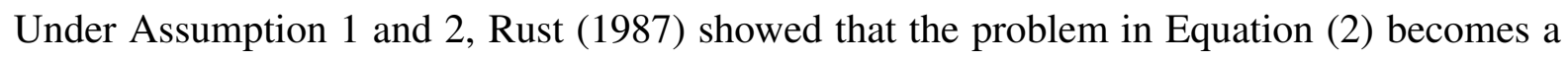
random utility model. Using the McFadden result that a random utility model under Assumption [ has a Logit representation, Rust showed that the conditional choice probabilities has the following Logit representation,

$$
\begin{aligned}
P(a \mid x) & =\frac{e^{\tilde{v}(x, a)}}{\sum_{a^{\prime} \in A(x)} e^{\tilde{v}\left(x, a^{\prime}\right)}}, \text { where } \\
\tilde{v}(x, a) & =u(x, a)+\beta F(x, a)\left[I_{m}-\beta \bar{F}\right]^{-1}[\bar{u}+\bar{e}]
\end{aligned}
$$

where $I_{m}$ is a $m \times m$ identity matrix, $\bar{F}$ is an $m \times m$ matrix with the element in the $\left(x, x^{\prime}\right)$ position is $\sum_{a \in A(x)} f\left(x^{\prime} \mid x, a\right) P(a \mid x) ; \bar{u}=\left[\bar{u}\left(x_{1}\right), \ldots, \bar{u}\left(x_{m}\right)\right]^{\prime}$, and $\bar{e}=\left[\bar{e}_{1}\left(x_{1}\right), \ldots, \bar{e}_{m}(x)\right]^{\prime}$ are $m$ dimensional column vectors with elements $\bar{u}(x)=\sum_{a \in A(x)} u(x, a) P(a \mid x)$ and $\bar{e}(x)=$ $\sum_{a \in A(x)} e(x, a) P(a \mid x), x \in \mathcal{X}$.

The question is, given our data how do we estimate the structural parameters, and hence choose a particular model to study all the policy issues? We explain this in the next section.

\section{Econometric implementation}

For each vector of structural parameters, we need compute the optimal choice probabilities $\mathcal{P}=$ $\{P(a \mid x), a \in A(x), x \in \mathcal{X}\}$ and use them to compute the likelihood of the sample and the maxi- 
mum likelihood estimates of the structural parameters. To that end, Rust (1987) used a fixed point algorithm on the set of functions to compute the value function, and used the value function to compute the optimal choice probabilities. Hotz and Miller (1993) use the fixed point algorithm for the choice probabilities and used these choice probabilities to compute the value function. For other estimation procedures, see a recent survey of the literature by Aguirregabiria and Mira (2010). We follow the Hotz and Miller approach to estimate the structural parameters as outlined below.

Based on what is known in the child-development literature, we specify the stochastic production functions for cognitive and non-cognitive skills as follows:

$$
\begin{aligned}
f_{\gamma}\left(x^{\prime} \mid x, a\right)= & q_{\tau}\left(\tau^{\prime} \mid \tau, s, a\right) \times q_{\sigma}\left(\sigma^{\prime} \mid \tau^{\prime}, \tau, \sigma, \mu, \eta, \phi, s, a\right) \\
& \times q_{\mu}\left(\mu^{\prime} \mid \tau^{\prime}, \tau, \sigma, \mu, \eta, \phi, s, a\right) \times q_{\eta}\left(\eta^{\prime} \mid \tau^{\prime}, \tau, \sigma, \mu, \eta, \phi, s, a\right) \\
& \times q_{\varphi}\left(\varphi^{\prime} \mid \tau^{\prime}, \tau, \sigma, \mu, \eta, \phi, s, a\right) \times q_{s}\left(s^{\prime} \mid \tau^{\prime}, \sigma^{\prime}, \mu^{\prime}, \eta^{\prime}, \phi^{\prime}, s, a\right)
\end{aligned}
$$

where each component probability density function is further specified as a Logit model with the regressors as the conditioning variables of the component. The details of the production process are discussed in section 4.4. Denote by $\gamma$ the vector of all of these regression parameters, which together determine the transition probabilities $f_{\gamma}\left(x^{\prime} \mid x, a\right)$. Denote the parameters of the reward function, $\theta$ and the altruism parameter $\beta$ by the vector $\xi=(\theta, \beta)$.

We have data of the type $\left(x_{i}, a_{i}, x_{i}^{\prime}\right), i=1, \ldots, n$, on $n$ parent-child pairs. The problem is to estimate the structural parameters $\zeta=(\xi, \gamma)$ using this data.

Note that for fixed $\zeta$, Equation (5), defines a map $\Psi: \Delta \rightarrow \Delta$ since the right hand side of the 
equation is a function of conditional probabilities. The fixed point of which is the set of conditional choice probabilities of the dynamic programming problem in Equation (D). It can be shown that for each structural parameter $\zeta$, the iterative process $\mathcal{P}_{n}=\Psi\left(\mathcal{P}_{n-1}\right)$, starting from any initial $\mathcal{P}_{0}$, always converges to a unique fixed point $\mathcal{P}_{\zeta}=\left(P_{\zeta}(a \mid x), a \in A(x), x \in \mathcal{X}\right)$. We use this $\mathcal{P}_{\zeta}$ to calculate the log-likelihood of the sample in the following procedure.

First note that $\operatorname{Pr}\left(a, x^{\prime} \mid x\right)=\operatorname{Pr}(a \mid x) \cdot \operatorname{Pr}\left(x^{\prime} \mid x, a\right)=P_{\zeta}(a \mid x) \cdot f_{\gamma}\left(x^{\prime} \mid x, a\right)$. The log-likelihood function for the sample is then given by $L(\xi, \gamma)=L_{1}(\xi, \gamma)+L_{2}(\gamma)$, where $L_{1}(\xi, \gamma)=$ $\sum_{i=1}^{n} \ln P_{\zeta}\left(a_{i} \mid x_{i}\right)$ and $L_{2}(\gamma)=\sum_{i=1}^{n} \ln f_{\gamma}\left(x_{i}^{\prime} \mid x_{i}, a_{i}\right)$. The full information maximum likelihood estimation involves maximizing the full likelihood $L(\xi, \gamma)$. The maximization of the full information likelihood involves numerous parameters. The maximization algorithm does not always converge and this turned out to be true in our case.

We follow a two-stage procedure instead. In the first stage we compute a consistent estimate $\hat{\gamma}$ by maximizing the conditional likelihood $L_{2}(\gamma)$, which given the recursive structure in Equation (5), is equivalent to estimating the individual logit models constituting the parts of $f_{\gamma}\left(x^{\prime} \mid x, a\right)$. We then estimate $\xi$ by maximizing $L_{1}(\xi, \hat{\gamma})$.

Denote this two stage estimate by $\left(\hat{\xi}_{r}, \hat{\gamma}_{r}\right)$ and the full information maximum likelihood estimate by $\left(\hat{\xi}_{f}, \hat{\gamma}_{f}\right)$. How close is the estimate $\hat{\xi}_{r}$ to $\hat{\xi}_{f}$ ? How precise is the estimate of the standard error $\sum_{\xi \xi \cdot \gamma}$ of $\hat{\xi}_{r}$ obtained from the restricted maximum likelihood procedure by fixing a value of $\gamma=\hat{\gamma}_{r}$ 
Cox and Wermuth (1990) showed that up to a first order approximation, we have

$$
\begin{aligned}
\hat{\xi}_{r}-\hat{\xi}_{f} & \approx I_{\xi \xi}^{-1} I_{\xi \gamma}\left(\hat{\gamma}_{f}-\hat{\gamma}_{r}\right) \\
\Sigma_{\xi \xi \cdot \gamma} & =\Sigma_{\xi \xi}-\Sigma_{\xi \gamma} \Sigma_{\gamma \gamma}^{-1} \Sigma_{\gamma \xi}=I_{\xi \xi}^{-1}
\end{aligned}
$$

where the information matrix and the variance-covariance matrix are

$$
\begin{aligned}
& I(\xi, \gamma) \stackrel{\text { def }}{=}-E\left(\begin{array}{cc}
\frac{\partial^{2} L(\xi, \gamma)}{\partial \xi^{2}} & \frac{\partial^{2} L(\xi, \gamma)}{\partial \xi \partial \gamma} \\
\frac{\partial^{2} L(\xi, \gamma)}{\partial \gamma \partial \xi} & \frac{\partial^{2} L(\theta, \gamma)}{\partial \gamma^{2}}
\end{array}\right) \stackrel{\text { notation }}{=}\left[\begin{array}{cc}
I_{\xi \xi} & I_{\xi \gamma} \\
I_{\gamma \xi} & I_{\gamma \gamma}
\end{array}\right], \\
& I^{-1}(\xi, \gamma) \stackrel{\text { notation }}{=}\left[\begin{array}{cc}
\Sigma_{\xi \xi} & \Sigma_{\xi \gamma} \\
\Sigma_{\gamma \xi} & \Sigma_{\gamma \gamma}
\end{array}\right]
\end{aligned}
$$

Note that $\Sigma_{\xi \xi}$ would be the variance covariance matrix of the full information maximum likelihood estimate $\hat{\zeta}_{f}$.

Since our $\hat{\gamma}_{r}$ is a consistent estimator for $\gamma$, from the first line of Equation (पD) we know that we have zero asymptotic bias for our estimates. But from the second line of Equation (प) we see that our standard errors are smaller, i.e., our $t$-statistics are larger than that of the full information maximum likelihood estimators. We use the public domain Sun Java programming language to implement the above estimation procedure and for all other computational tasks. 


\section{Empirical Findings}

\subsection{The Dataset and the Variables}

We use the NLSY79 and the NLSY79 Children and Young Adults data. The NLSY79 dataset contains a nationally representative sample of 12,686 young men and women who were 14-22 years old when they were first surveyed in 1979, i.e., these sampled individuals represent a population born in the 1950s and 1960s, and living in the United States in 1979. These individuals are interviewed annually. The dataset has records of school and labor market experiences of these individuals and also the information on their cognitive and non-cognitive traits. We, however, need information on most of these variables for the parents of the respondents. This dataset does not have much information on respondents' parents. So we link this dataset with the NLSY79 Children and Young Adults dataset. The child survey dataset includes longitudinal assessments of each child's cognitive, attitudinal and social, motivational, academic and labor market experiences. We construct the variables of our study as follows:

Early childhood inputs and home environment: We take the father's and mother's education levels to measure the child's family background. The NLSY dataset has poor measures of respondent's early childhood inputs. It has only a binary variable containing information on whether the respondent had preschool (which does not include Head Start) experience or not. We treat individuals with Head Start as having no preschool in our analysis. Notice that this may lead to underestimation of the effect of preschool investment. We use the revised AFQT score to measure innate ability. 
Socialization skill $(\sigma)$ : Each respondent was asked how social towards others he/she felt at age

6 , expressed in the scale of 1 to 4 , the highest number represents most social. We create a binary sociability variable by assigning the value 1 if a respondent reported a value of 3 or 4 and assigning 0 otherwise.

Motivational skill $(\mu)$ : We measure motivational skill as the job aspiration of the respondents in the main NLSY79 sample. For the children sample, we have taken the average of the various motivation measures at young ages of the child and assigned a value 1 if it the average is larger than 3.75 and 0 otherwise.

Rosenberg measure of self-esteem skill $(\eta)$ : It measures the positiveness with which individuals regard themselves in society, i.e., a positive sense of self. Six questions were taken from the classic Rosenberg (1965) scale in the NLSY surveys. There is, however, no well accepted definition of adequate self-esteem. Based on the distribution, we divided the 25-point scale by treating a score of 20 or greater to indicate a high self-esteem, assigning a value 1 to $\eta$ and a value 0 to $\eta$ otherwise.

Pearlin mastery scale of internal self-concept $(\phi)$ : This measures the extent to which an individual believes that his life chances are under his own control (Pearlin et al, 1981). This is similar to Rotter scale of self-control. The respondents were asked seven questions yielding scores ranging from 0 to 28 . We assign the value 1 representing a high sense of self-control to respondents with a score between 23 and 28 inclusive, otherwise we assign a value 0 . For further discussion of these measures see Duckworth, Almlund, Kautz, and Heckman (Duckworth et al.). 


\subsection{An Augmented Earnings Function - The Role of cognitive and non-}

\section{cognitive skills}

Noncognitive traits are important determinants of both earnings and learning. For surveys of the effect of noncognitive traits on earnings see Borghans et al. (2008) and Almlund et al. (2011). We carry out a rudimentary analysis in this section to emphasize the importane of these traits for earnings. We estimate an augmented Mincer earnings function by adding measures of noncognitive skills such as social, motivational, self-esteem and internal self-concept skills in the standard Mincer earnings function that includes only cognitive skills such as innate ability and the number of years of schooling. As a byproduct, we provide an estimate of how much of the rate of returns to education in the standard Mincer earnings function is over estimated because the schooling level which is correlated with the omitted non-cognitive skill variables captures the effects of the non-cognitive skills.

Mincer (1958) showed that if foregone earnings is the only cost of schooling, and the effect of an extra year of schooling on earnings is proportional and constant, then the log of earnings is a linear function of the number of years of schooling. He later extended this model by allowing experience (measured by the square of the age of the worker) to affect earnings over the life-cycle as follows:

$$
\ln w=\alpha_{0}+\alpha_{1} s+\alpha_{2} \text { age }+\alpha_{3} \text { age }^{2}+\varepsilon
$$

This basic Mincer earnings function has been estimated using various datasets. It has been given various interpretations by deriving it from various models of schooling choice, see for in- 
stance Card (1999); Heckman et al. (2006, 2008); Weiss (1995). We estimate the basic model taking $w$ to be the annual earnings of the respondents in the NLSY79 dataset. The estimates for this basic model are reported in the second column (with the heading "Basic") in Table W. Our estimate for $\alpha_{1}$ is 11.12 percent which is close to what is found in other studies, see for instance the survey by Card (1999), and the analyses of Heckman et al. (2006, 2008)

What exactly is the role of education in the production of earnings? Does an extra year of education have any intrinsic value in the production of output? Or is it a surrogate for other factors such as innate ability and hence the estimated returns to education is higher than its actual worth in production?

We include the AFQT score variable as a regressor, which is a widely used measure of ability, together with other standard variables used in the literature such as family background measured by the parents' education levels, and a dummy variable for the female gender. These are reported in the third column (with the heading of "Extended") in Table $\mathbb{W}$. The estimate for the schooling coefficient drops to 6.94 percent. This estimate is corrected for ability bias or gender bias in the estimated returns to schooling and close to what is found in other studies, see Card (1999). We now add to it our four measures of non-cognitive skills to see how much of the above estimate of the returns to education is biased upward because it is capturing the effects of the omitted

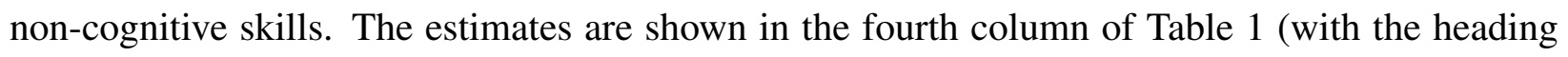
"Augmented"). We see that all of the four non-cognitive skill variables have significant positive effects on earnings and the rate of returns to education has dropped by about 1 percent point. By

\footnotetext{
${ }^{5}$ See Borghans et al. (2011); Heckman and Kautz (2012) for limitations of this measure.
} 
looking at the $R^{2}$ values, we see that about 1 percent variation in earnings is explained by the inclusion of the non-cognitive skills in the standard Mincer earnings function.

\subsection{Estimation of Schooling Function}

We consider two specifications of the schooling function, $s\left(\tau^{\prime}, \sigma^{\prime}, \mu^{\prime}, \eta^{\prime}, \phi^{\prime}, a, \varepsilon^{\prime}\right)$. In the first specification, we assume that the schooling level is a continuous variable and the function $s\left(\tau^{\prime}, \sigma^{\prime}, \mu^{\prime}, \eta^{\prime}, \phi^{\prime}, a, \varepsilon^{\prime}\right)$ is linear. We assume that the variable $\varepsilon^{\prime}$ constitutes an additive error term and satisfies all the assumptions of the OLS model. ${ }^{\text {G }}$ We included our measures of cognitive and non-cognitive skills and the family background. The parameter estimates from this model are shown in table 2 .

In our second specification, we consider only two levels of schooling: $s=1$ for completed college or more, and $s=0$ otherwise. We assume that $s\left(\tau^{\prime}, \sigma^{\prime}, \mu^{\prime}, \eta^{\prime}, \phi^{\prime}, a, \varepsilon^{\prime}\right)$ is a Logit model. The parameter estimates from this model are shown in table 2 .

It is clear from the estimates that the most significant determinant of schooling is the innate ability measured by AFQT score. Moreover, even after controlling for the family background, we find that all non-cognitive skills have significant positive effects on schooling level.

\subsection{Production of non-cognitive skills}

As established in the cited literature, non-cognitive skills are important determinants of earnings and learning. In this section we estimate the production process of these skills and estimate the

\footnotetext{
${ }^{6}$ More generally we could assume that $E\left(\varepsilon_{s}^{\prime} \mid \tau^{\prime}, \sigma^{\prime}, \mu^{\prime}, h\right)=0$ and use GLS method to correct for heteroskedasticity.
} 
Table 1: Determinants of earnings - role of cognitive and non-cognitive skills (from the parent sample)

\begin{tabular}{||l||c|c|c|}
\hline \hline Variables & Basic & Extended & Augmented \\
\hline \hline Intercept & 1.7137 & 2.3440 & 1.6978 \\
& $(28.22)$ & $(36.36)$ & 25.12 \\
\hline Grade* & 0.1112 & 0.0694 & 0.0595 \\
& $(82.59)$ & $(37.93)$ & $(31.93)$ \\
\hline Age & 0.3363 & 0.3277 & 0.3279 \\
& $(82.66)$ & $(77.00)$ & $(76.77)$ \\
\hline Age Square & -0.0040 & -0.0039 & -0.0039 \\
& $(60.79)$ & $(56.45)$ & $(56.30)$ \\
\hline Mother's grade & & -0.0022 & -0.0050 \\
& & $(1.61)$ & $(3.59)$ \\
\hline Father's Grade & & 0.0079 & 0.0065 \\
& & $(7.00)$ & $(5.67)$ \\
\hline Dummy variable for Female & & -0.5187 & -0.5137 \\
& & $(81.19)$ & $(79.70)$ \\
\hline Dummy Variable for non-Black & & 0.0545 & 0.0794 \\
and non-Hispanic & & $(7.21)$ & $(10.39)$ \\
\hline$\tau:$ Revised AFQT Score & & 0.0059 & 0.0048 \\
& & $(36.76)$ & $(28.90)$ \\
\hline$s:$ Socialisation & & & 0.0111 \\
& & & $(1.68)$ \\
\hline$\mu:$ Motivation - Job Aspiration & & & 0.0261 \\
& & & $(3.57)$ \\
\hline : Self-Esteem (Rosenberg Scale) & & & 0.0193 \\
& & & $(18.24)$ \\
\hline$R^{2}$ & & & 0.0251 \\
& & & 93,166 \\
\hline
\end{tabular}

Notes: Absolute values of $t$-statistics are in parentheses. 
Table 2: Determinants of grade and College completion - role of cognitive and non-cognitive skills (from the parent sample)

\begin{tabular}{||l||c|c||}
\hline \hline Variables & $\begin{array}{c}\text { OLS model of years } \\
\text { of completed schooling }\end{array}$ & $\begin{array}{c}\text { Logit model of } \\
\text { completing college }\end{array}$ \\
\hline \hline Intercept & 9.1570 & -7.9304 \\
& $(421.47)$ & $(117.45)$ \\
\hline Mother's grade & 0.0817 & 0.1145 \\
& $(35.79)$ & $(23.76)$ \\
\hline Father's Grade & 0.0430 & 0.0705 \\
& $(22.84)$ & $(19.59)$ \\
\hline$\tau:$ Revised AFQT Score & 0.4999 & 0.5800 \\
& $(35.89)$ & $(24.72)$ \\
\hline$\sigma:$ Socialisation & 0.0384 & 0.0472 \\
& $(169.00)$ & $(104.15)$ \\
\hline$\mu:$ Motivation - Job Aspiration & 0.0776 & 0.1332 \\
& $(7.00)$ & $(6.80)$ \\
\hline$\eta:$ Self-Esteem (Rosenberg Scale) & 0.4890 & 0.9446 \\
& $(40.69)$ & $(34.09)$ \\
\hline$\phi:$ Internal Self-Control (Pearlin scale) & 0.3551 & 0.3781 \\
& $(21.39)$ & $(14.66)$ \\
\hline $\mathrm{n}$ & 0.4399 & 0.7299 \\
\hline$R{ }^{2} *$ & $(31.32)$ & $(20.62)$ \\
\hline \hline
\end{tabular}

* Notes: The $R^{2}$ in the second column is the McFadden's- $R^{2}$. 
effect of preschool experience on the production of these non-cognitive skills.

The literature in sociology, psychology, early childhood development and physiology suggest that early childhood investment is the most crucial input for development of cognitive and noncognitive skills. (See Cunha and Heckman, 2007, 2009; Heckman et al., 2008)

We create the binary variable $\tau$ assigning the value 1 to denote an individual as highly talented if the AFQT score of the individual is 70 or higher (in a scale of 0 to 100), and assigning the value $\tau=0$ otherwise. Other binary skill variables are described earlier. We estimated the Logit models for each of the cognitive and non-cognitive skills types on the children sample. These parameter estimates constitute the components of the parameter vector $\gamma$ of the transition probability function $f_{\gamma}\left(x^{\prime} \mid x, a\right)$. We report the parameter estimates in table B for the specifications of each components of $x$ and $a$. These are used in the two-step estimation procedure to estimate $\xi=(\theta, \beta)$ given the parameters $\gamma$ of the transition probability function fixed at these estimates. To compare the sensitivity of our estimates and inference of the structural parameters, we estimated another specification in which we included only those regressors that are significant.

From table B, it is clear that after controlling for parents' grade, preschool has significantly positive effect on the socialization skill, and on the levels of talent and schooling. But it has no effect on Pearlin measure of internal self-concept and the Rosenberg measure of self-esteem. The estimates in the table also show that the level of talent has strong positive effects on the formation of all skills. 
Table 3: Logit model of cognitive and non-cognitive skills.

\begin{tabular}{||l||c|c|c|c|c|c||}
\hline \hline Variables & $\tau^{\prime}$ & $\sigma^{\prime}$ & $\mu^{\prime}$ & $\eta^{\prime}$ & $\phi^{\prime}$ & $s$ \\
\hline \hline Intercept & -2.8005 & -1.1219 & -0.8990 & -2.5222 & -2.7063 & -3.9698 \\
& $(41.76)$ & $(20.80)$ & $(17.02)$ & $(32.42)$ & $(32.61)$ & $(33.60)$ \\
\hline$\tau$ & 1.4300 & 0.1508 & -0.0713 & -0.5082 & -0.4989 & 2.1359 \\
& $(23.99)$ & $(2.47)$ & $(1.19)$ & $(6.99)$ & $(6.69)$ & $(26.38)$ \\
\hline$\tau^{\prime}$ & & 0.9459 & 1.2590 & 0.2423 & 0.1800 & \\
& & $(16.78)$ & $(22.85)$ & $(4.18)$ & $(3.04)$ & \\
\hline$\sigma$ & & 0.2414 & 0.1940 & 0.1209 & 0.1044 & 0.3041 \\
& & $(5.64)$ & $(4.62)$ & $(2.54)$ & $(2.14)$ & $(3.92)$ \\
\hline$\mu$ & & 0.1005 & -0.0211 & -0.0449 & -0.0312 & 0.7126 \\
& & $(2.26)$ & $(0.48)$ & $(0.89)$ & $(0.61)$ & $(6.78)$ \\
\hline$\eta$ & & 0.2581 & 0.2577 & 0.2863 & 0.2542 & 0.5727 \\
& & $(5.82)$ & $(5.91)$ & $(5.90)$ & $(5.13)$ & $(7.31)$ \\
\hline$S$ & & -0.0177 & -0.0466 & 0.1294 & 0.1333 & 0.6198 \\
& & $(0.41)$ & $(1.11)$ & $(2.66)$ & $(2.68)$ & $(7.72)$ \\
\hline a : Preschool & 0.8766 & 0.7972 & 0.0496 & -0.0731 & -0.0647 & 0.6569 \\
& $(16.75)$ & $(18.58)$ & $(1.16)$ & $(1.53)$ & $(1.33)$ & $(7.13)$ \\
\hline $\mathrm{n}$ & 11,428 & 11,428 & 11,428 & 11,428 & 11,428 & 7,732 \\
\hline McFadden's- ${ }^{2}$ & 0.109 & 0.0911 & 0.0623 & 0.0681 & 0.0705 & 0.2205 \\
\hline
\end{tabular}

Notes: A variable $x$ without a ' refers to the parent and with a ' refers to his child.

$\tau:$ Revised AFQT Score

$\sigma$ : Socialisation

$\mu$ : Motivation - Job Aspiration

$\eta$ : Self-Esteem (Rosenberg Scale)

$\phi:$ Internal Self-Control (Pearlin Scale)

While for other models the attributes Socialization, Motivation, Internal Self-concept (Pearlin) and Self-esteem (Rosenberg) in the first column are parents' attributes, for the schooling model s, these attributes in column one are the individual's own attributes, and this model is estimated using the 1979 youth sample. 


\subsection{Optimal Parental Preschool Investment Decision}

We assume that the state variables $s, \tau, \sigma, \mu, \eta$ and $\phi$ are all binary, the components of the random variable $\varepsilon$ are continuous and the preschool investment choice $a$ is a binary variable, taking value 1 if the parent decides to invest in preschool and taking value 0 otherwise. For many children in our sample, we have two parents alive, but in our model we have assumed one parent family.

We use both parents' information to create a synthetic parent as follows: We construct a parent's binary schooling variable $s$ to take value 1 if either parent has 16 or more years of education, otherwise $s=0$.

We define a parent to fall in the poor SES if his earnings is less than 70 percent of the average earnings in economy. We consider a public policy of providing preschool to children of poor socioeconomic status (SES) in all periods. This will impose a tax burden on all parents, but such policy may also improve the social mobility, reduce the earnings inequality and eventually lead to a higher level of per capita earnings in the long-run. We examine if the gain from per capita earnings can outpace the cost of providing such a social insurance program. We also look at its within generation effects on earnings, and on the intergenerational effects on earnings and college mobility.

The two-step maximum likelihood estimates of the structural parameters $\xi=(\theta, \beta)$ are shown in table 4 for two sets of specifications of the transition probabilities $f_{\gamma}\left(x^{\prime} \mid x, a\right)$ - the first column contains the estimates from the specification in which only the significant conditioning variables are included, and the second column contains the estimates of the parameters in which all the 
conditioning variables are included. The table also reports the percent of parents falling into the poor SES status in the long-run before and after the introduction of the public policy and the tax rate $\tau$ that finances the public preschool policy in the long-run equilibrium. Furthermore, the table also reports the long-run disposable (i.e., after tax) average yearly earnings of workers before and after the introduction of the social contract policy.

An estimate of $\hat{\theta}=1.224$ in the table means that the cost per year during the first five preschool years is $\$ 6,120$. This comes from the fact we have annualized earnings over 25 years of life-cycle and a total preschool cost of $\$ 30,600=\$ 1,224 \times 25$ is spread out uniformly over the first five years of the child's preschool age. Schweinhart et al. reported an estimate of the average yearly preschool cost to be $\$ 6,178$ using the actual preschool cost. Our maximum likelihood estimate of the cost is very close to their direct estimate of cost.

Table 4: Maximum likelihood parameter estimates of $\xi=(\theta, \beta)$ given two different estimates of $f_{\gamma}\left(x^{\prime} \mid x, a\right)$..

\begin{tabular}{|c|c|c|}
\hline & \multicolumn{2}{|c|}{ Given estimates of $f_{\gamma}\left(x^{\prime} \mid x, a\right)$ with } \\
\hline & only significant $x$ & all $x$ \\
\hline $\begin{array}{l}\text { Cost }(\hat{\theta}) \text { of preschool (in '000 dollars) } \\
t \text {-stat }\end{array}$ & $\begin{array}{c}1.222 \\
(31.390)\end{array}$ & $\begin{array}{c}1.224 \\
(31.29)\end{array}$ \\
\hline $\begin{array}{l}\text { Degree of altruism: } \hat{\beta} \\
t \text {-stat }\end{array}$ & $\begin{array}{c}0.444 \\
(4.945)\end{array}$ & $\begin{array}{c}0.486 \\
(5.56)\end{array}$ \\
\hline Long-run Equibrium Tax Rate: $\tau$ (in percent) & 5.94 & 5.83 \\
\hline $\begin{array}{l}\text { Percent of population in poor SES: } \\
\text { Before the policy introduction }(\tau=0) \\
\text { After the policy introduction }\end{array}$ & $\begin{array}{l}36.22 \\
29.64\end{array}$ & $\begin{array}{l}35.71 \\
29.14\end{array}$ \\
\hline $\begin{array}{l}\text { Per capita after tax annual earnings: } \\
\text { Before the policy introduction }(\tau=0) \\
\text { After the policy introduction }\end{array}$ & $\begin{array}{l}5,621.85 \\
5,734.93\end{array}$ & $\begin{array}{l}5,640.08 \\
5,759.38\end{array}$ \\
\hline Log-likelihood & -7424.97 & -7429.575 \\
\hline
\end{tabular}

Note: Absolute values of $t$-statistics are in parentheses. 


\section{Economic Benefits from Public Provision of Preschool}

We have shown that investment in preschool enhances certain skills that are important for learning and earning. We have also seen that very few parents of poor SES invest in their children's preschool. If preschool is publicly provided for the children of poor SES, it will have many economic benefits: It will increase social mobility, it will reduce income inequality, it will improve college enrollment rate, it will improve the community or criminal behavior, and it will also bring higher tax revenues because more workers will be earning higher wages. It is important to note that the magnitude of the effect of publicly provided preschool will depend on if the social protection will be available to all future generations or it is just a one time policy. (See Heckman and Masterov, 20(04)

While looking at the magnitudes of the estimated economic benefits below, it is important to keep in mind that the effects that we report in this paper are underestimates for many reasons: First, we have treated the Head Start children same as children without preschool. Second, the preschool programs that the respondents attended were the ones that existed during the sixties. The quality of preschool programs since then has improved significantly and thus the effects of current preschool programs will be much higher than the estimates that we have.

\subsection{Intergenerational Earnings Mobility}

To examine how the introduction of the public policy that provides free preschool to children of poor SES, affect earnings mobility between generations, we computed the mobility index of the 
stationary transition probability matrix of the equilibrium Markov process of earnings distributions over time. Our estimate of the measure of earnings mobility before the introduction of the social contract is 0.5945 and after the introduction of the public preschool program is 0.6468 .

It is difficult to compare our estimate of the mobility index with previous studies because there is no commonly agreed upon measure of earnings mobility. For a survey of various measures of mobilities and their properties, see Geweke et al. (1986).

\subsection{College Mobility}

Denote by $Q^{s}=\left[q_{i j}\right], i, j=1,2$, the intergenerational college mobility matrix in which state 1 represents no college and state 2 represents college or more. The element $q_{i j}$ represents the probability that a child of a parent of college education status $i$ will move to the college education status $j$, for all $i$ and $j=1,2$. We report below the estimated college mobility matrices, the corresponding invariant distributions, and the estimates of the mobility measure before and after the introduction of the social contract. These estimates indicate that the introduction of the social contract will increase college enrollment from a 6.71 percent to a 9.45 percent, i.e. a 2.73 percentage point increase for a child of non-college parent. And the percentage of college educated population will increase in the long-run from the rate of 10.16 percent without social contract to a higher rate of 13.76 percent with the social contract. That is, there will be about a $3.6 \%$ increase in the college enrollment in the long-run.

\section{College mobility statistics before introduction of social contract:}




$$
Q_{b}^{s}=\left[\begin{array}{ll}
0.93287 & 0.06713 \\
0.59380 & 0.40620
\end{array}\right], p_{b}^{s}=\left[\begin{array}{ll}
0.8984 & 0.1016
\end{array}\right], 1-\lambda_{\max , b}^{s}=0.6609
$$

\section{College mobility statistics after introduction of social contract:}

$$
Q_{a}^{s}=\left[\begin{array}{ll}
0.90553 & 0.09447 \\
0.59184 & 0.40816
\end{array}\right], p_{a}^{s}=\left[\begin{array}{ll}
0.8624 & 0.1376
\end{array}\right], 1-\lambda_{\max , a}^{s}=0.6863
$$

\subsection{Lifetime Earnings Inequality}

Preschool investment would increase the incomes of the children of poor SES families and thus it will reduce the income gap between the rich and the poor. Using the Gini-coefficient to measure income inequality, we would expect that over time income inequality will improve. The longrun income distribution that one observes is the invariant distribution. We compute the Ginicoefficient of income inequality for the invariant income distribution before the introduction of the public policy and compare it with the Gini-coefficient for the invariant income distribution after the introduction of the policy. The estimated Gini-coefficients are respectively 0.2363 without the social contract, and 0.2335 with the social contract. The estimated Gini-coefficient of average lifetime earnings is 0.2363 . We note that the social contract of publicly providing preschool to children of poor SES produces a reduction in the inequality of the long-term earnings. 
To compare our estimates to the literature, it is important to know that earnings in our model are averages over the life-cycle (it is 25 years in our data). Furthermore, we have earnings averaged over 64 income groups, whereas most studies in the literature have many more groups. The Gini coefficient decreases if it is applied to average earnings of groups. Keeping this in mind, our estimates are comparable to estimates in the literature. For instance, Leigh (2009) estimates the Gini coefficient of ten years average earnings over the life cycle to be little less than 0.3 in the 1990's and around 0.35 for annual earnings in the 1990s.

\subsection{The Tax Burden of the Social Policy}

Suppose the government provides preschool to the children of poor SES perpetually. We know that the size of the population of poor SES will become smaller over time. Thus the resource needs of the program will become smaller, and the tax revenues will become higher over time. We can look at the stream of these costs and benefits to the society and then compute the average per period costs and benefits to calculate the tax-burdens of the social contract. Applying the Ergodic theorem, this boils down to computing the costs and benefits of the invariant distribution that will result after the introduction of the social contract. Our computations below are based on the long-run equilibrium.

Without the public policy, approximately 35.71 percent of the population in the long-run will fall in the poor socioeconomic status, using our definition of poor SES. The introduction of the public policy will reduce the population in the poor SES to 29.14 percent. From table 5, we see that while the welfare of the income groups that get publicly provided preschool will be higher, the welfare of the rest of the population will be lower. It is difficult to estimate the net effect of 
the policy on social welfare since there is no universally agreed upon aggregation rule for social welfare. We use the average yearly disposable earnings over the life-cycle to compare the net gain or loss to the society. These estimates in table 4 show that the average yearly disposable earnings of the society in the long-run is higher by $\$ 113$ after the introduction of the policy. Based on this we conclude that there is a net gain to the society of introducing such a publicly provided preschool program for the children of poor SES.

Our benefit calculation does not take into account other public savings that will result due to the policy such as savings from welfare assistance programs and savings to the criminal justice system and potential victims of crimes. If we incorporate these, the returns will be much higher. Using data from the High/Scope Perry Preschool Program, Heckman et al. (2010b) estimate a total benefit of 7 percent from all these sources for each dollar spent on the preschool program even counting for the social costs of taxation.

\section{Conclusion}

This paper formulates an altruistic model of preschool investment choices of parents in a structural dynamic programming framework. It uses the NLSY79 and NLSY79 Children and Young Adult data to estimate the structural parameters

The paper estimates the production processes of two types of cognitive skills - the IQ score and the schooling level, and four types of non-cognitive skills - the socialization skill, the motivational skill, the Rosenberg measure of self-esteem skill and the Pearlin mastery scale of internal self- 
concept skill. The paper finds that the preschool boosts significantly both types of cognitive skills and only the socialization skills among the four measures of non-cognitive skills. Moreover, all these cognitive and non-cognitive skills have significant positive effects on the level of schooling and the labor market earnings of individuals.

The paper estimates the structural parameters and then used those to carry out a Marschak (1953)-Lucas (1976)-Critique free policy analysis to examine the effect of a publicly provided preschool to economically disadvantaged children and financing it by taxing all parents. Taking into account the within generation and between generations effects of such a policy, the paper finds that introduction of such a public policy (a) improves the intergenerational earnings mobility from 0.5945 to 0.6468 , measured in a scale of 0 to 1 , (b) improves the college mobility from 0.6609 to 0.6863 , measured in a scale of 0 to 1 , (c) increases the college completion rate of the children of non-college educated parents from 10.16 percent to 13.76 percent, i.e., a 3.6 percentage point increase, (d) reduces the within generation earnings inequality measured by the Gini coefficient in a scale of 0 to 1 from 0.2363 to 0.2335 , and (e) there is a net gain (net of taxes) in the long-run per capita earnings.

The positive effects of the public preschool policy will be even higher in reality because we have used the estimated benefits from the lower quality preschool programs that existed in the 1970s. 


\section{References}

Aguirregabiria, V. and P. Mira (2010). Dynamic discrete choice structural models: A survey. Journal of Econometrics 156(1), 38-67. B

Almlund, M., A. Duckworth, J. J. Heckman, and T. Kautz (2011). Personality psychology and economics. In E. A. Hanushek, S. Machin, and L. Wößmann (Eds.), Handbook of the Economics of Education, Volume 4, pp. 1-181. Amsterdam: Elsevier. [, 4.2

Bhattacharya, R. N. and M. Majumdar (1989). Controlled semi-markov models: The discounted case. Journal of Statistical Planning and Inference 21(3), 365-381. 口

Boca, D. D., C. J. Flinn, and M. Wiswall (2013). Household choices and child development. Review of Economic Studies, Forthcoming. [

Borghans, L., A. L. Duckworth, J. J. Heckman, and B. ter Weel (2008, Fall). The economics and psychology of personality traits. Journal of Human Resources 43(4), 972-1059. 4.2

Borghans, L., B. H. H. Golsteyn, J. J. Heckman, and J. E. Humphries (2011). Identification problems in personality psychology. Personality and Individual Differences 51(3: Special Issue on Personality and Economics), 315-320. [

Campbell, F., G. Conti, J. Heckman, S. Moon, and R. Pinto (2012). The long-term health effects of early childhood interventions. Under review, Economic Journal. W 
Card, D. (1999). The causal effect of education on earnings. In O. Ashenfelter and D. Card (Eds.), Handbook of Labor Economics, Volume 5, pp. 1801-1863. New York: North-Holland. 4.2

Carneiro, P. and J. J. Heckman (2003). Human capital policy. In J. J. Heckman, A. B. Krueger, and B. M. Friedman (Eds.), Inequality in America: What Role for Human Capital Policies?, pp. 77-239. Cambridge, MA: MIT Press. [

Cox, D. R. and N. Wermuth (1990). An approximation to maximum likelihood estimates in reduced models. Biometrika 77(4), 747-761. [

Cunha, F. and J. J. Heckman (2007, May). The technology of skill formation. American Economic Review 97(2), 31-47. [, 4.4

Cunha, F. and J. J. Heckman (2008, Fall). Formulating, identifying and estimating the technology of cognitive and noncognitive skill formation. Journal of Human Resources 43(4), 738-782. ฉ

Cunha, F. and J. J. Heckman (2009, April). The economics and psychology of inequality and human development. Journal of the European Economic Association 7(2-3), 320-364. Presented as the Marshall Lecture, European Economics Association, Milan, Italy, August 29, 2008. ஐ, 4.4

Cunha, F., J. J. Heckman, L. J. Lochner, and D. V. Masterov (2006). Interpreting the evidence on life cycle skill formation. In E. A. Hanushek and F. Welch (Eds.), Handbook of the Economics of Education, Chapter 12, pp. 697-812. Amsterdam: North-Holland. W 
Cunha, F., J. J. Heckman, and S. M. Schennach (2010, May). Estimating the technology of cognitive and noncognitive skill formation. Econometrica 78(3), 883-931. [

Currie, J. and D. Thomas (1995, June). Does Head Start make a difference? American Economic Review 85(3), 341-364. [

Deming, D. (2009, July). Early childhood intervention and life-cycle skill development: Evidence from Head Start. American Economic Journal: Applied Economics 1(3), 111-134. W

Duckworth, A., M. Almlund, T. Kautz, and J. J. Heckman. The Relevance of Personality Psychology for Economics. Forthcoming, Handbook of the Economics of Education. 1, 4.]

Geweke, J., R. C. Marshall, and G. A. Zarkin (1986). Mobility indices in continuous time markov chains. Econometrica 54(6), 1407-1423. 5.]

Heckman, J. J. (2000, March). Policies to foster human capital. Research in Economics 54(1), 3-56. [1

Heckman, J. J. (2008, July). Schools, skills and synapses. Economic Inquiry 46(3), 289-324. W

Heckman, J. J., F. Flyer, and C. Loughlin (2008, January). An assessment of causal inference in smoking initiation research and a framework for future research. Economic Inquiry 46(1), 37-44. 4.4

Heckman, J. J. and T. Kautz (2012, August). Hard evidence on soft skills. Labour Economics 19(4), 451-464. Adam Smith Lecture. [, [] 
Heckman, J. J., L. J. Lochner, and P. E. Todd (2006). Earnings equations and rates of return: The Mincer equation and beyond. In E. A. Hanushek and F. Welch (Eds.), Handbook of the Economics of Education, Volume 1, Chapter 7, pp. 307-458. Amsterdam: Elsevier. 4.2

Heckman, J. J., L. J. Lochner, and P. E. Todd (2008, Spring). Earnings functions and rates of return. Journal of Human Capital 2(1), 1-31. 4.2

Heckman, J. J. and D. V. Masterov (2004, September). The productivity argument for investing in young children. Technical Report Working Paper No. 5, Committee on Economic Development. 5

Heckman, J. J., S. H. Moon, R. Pinto, P. A. Savelyev, and A. Q. Yavitz (2010a, August). Analyzing social experiments as implemented: A reexamination of the evidence from the HighScope Perry Preschool Program. Quantitative Economics 1(1), 1-46. [

Heckman, J. J., S. H. Moon, R. Pinto, P. A. Savelyev, and A. Q. Yavitz (2010b, February). The rate of return to the HighScope Perry Preschool Program. Journal of Public Economics 94(1-2), 114-128. [1, 5.4

Hotz, V. J. and R. A. Miller (1993, July). Conditional choice probabilities and the estimation of dynamic models. Review of Economic Studies 60(3), 497-529. [3

Leigh, A. (2009). Permanent income inequality: Australia, Britain, Germany, and the United States. Discussion Paper DP628, The Australian National University Centre for Economic Policy Research. 5.3 
Lucas, Jr., R. E. (1976). Econometric policy evaluation: A critique. In K. Brunner and A. H. Meltzer (Eds.), The Phillips Curve and Labor Markets, Volume 1 of Carnegie-Rochester Conference Series on Public Policy. New York: American Elsevier Publishing Company. 6

Marschak, J. (1953). Economic measurements for policy and prediction. In W. Hood and T. Koopmans (Eds.), Studies in Econometric Method, pp. 1-26. New York: Wiley. 6

Mincer, J. (1958, August). Investment in human capital and personal income distribution. Journal of Political Economy 66(4), 281-302. 4.2

Mohanty, L. L. and L. K. Raut (2009). Home ownership and school outcomes of children: Evidence from the PSID Child Development Supplement. American Journal of Economics and Sociology 68(2), 465-489. [

Nishimura, K. and L. K. Raut (2007). School choice and the intergenerational poverty trap. Review of Development Economics 11(2), 412-420. [

Pearlin, L. I., E. G. Menaghan, M. A. Lieberman, and J. T. Mullan (1981, December). The stress process. Journal of Health and Social Behavior 22(4), 337-356. 4.1

Raut, L. K. (1995). Signalling equilibrium, intergenerational mobility and long-run growth. Technical Report 9603002, EconWPA. Presented at the Seventh World Congress of the Econometric Society, Tokyo, Japan. 廿4

Raut, L. K. (2003). Long term effects of preschool investment on school performance and labor market outcome. Technical Report 0307002, EconWPA. [ 
Rosenberg, M. (1965). Society and the Adolescent Self-Image. Princeton, NJ: Princeton University Press. 4.1

Rust, J. (1987, September). Optimal replacement of GMC bus engines: An empirical model of Harold Zurcher. Econometrica 55(5), 999-1033. [, 2.1, 2.1, B]

Rust, J. (1994). Structural estimation of Markov decision processes. In R. Engle and D. McFadden (Eds.), Handbook of Econometrics, Volume, pp. 3081-3143. New York: North-Holland. 2.1

Schweinhart, L. J., H. V. Barnes, and D. Weikart (1993). Significant Benefits: The High-Scope Perry Preschool Study Through Age 27. Ypsilanti, MI: High/Scope Press. 4.5

Sommers, P. M. and J. Conlisk (1979). Eigenvalue immobility measures for Markov chains. Journal of Mathematical Sociology 6(2), 253-276. [

Traub, J. (2000). What no school can do. The New York Times Magazine January 16(Section 6), 52-57. [1

Weiss, A. (1995). Human capital vs. signalling explanations of wages. Journal of Economic Perspectives 9(4), 133-154. 4.2 


\section{APPENDIX}

Table 5: Equilibrium Solution

\begin{tabular}{|c|c|c|c|c|c|c|c|c|}
\hline State & PV Wage & obsd freq & $P_{b}(a=1 \mid x)$ & $\bar{P}_{a}(a=1 \mid x)$ & $\overline{\overline{\text { opt } V_{b}}}$ & $\overline{\mathrm{opt} V_{a}}$ & $p *_{b}$ & $p * a$ \\
\hline$[0,0,0,0,0,0]$ & 3.0993 & 9.5730 & 33.8937 & 100.0000 & 8.5885 & 8.8587 & 32.5119 & 26.1168 \\
\hline$[0,1,0,0,0,0]$ & 3.5662 & 3.6839 & 34.2812 & 100.0000 & 9.0979 & 9.3356 & 0.8377 & 0.9192 \\
\hline$[0,0,1,0,0,0]$ & 3.5977 & 17.8684 & 33.9587 & 100.0000 & 9.0866 & 9.3284 & 2.3604 & 1.9432 \\
\hline$[0,1,1,0,0,0]$ & 4.0646 & 6.4491 & 34.3223 & 33.7294 & 9.5959 & 9.3847 & 0.1404 & 0.1589 \\
\hline$[0,0,0,0,1,0]$ & 4.4821 & 3.4739 & 33.8578 & 33.2821 & 9.9837 & 9.7555 & 2.8119 & 2.2938 \\
\hline$[0,1,0,0,1,0]$ & 4.9490 & 1.2776 & 34.2534 & 33.6584 & 10.4946 & 10.2290 & 0.1549 & 0.1739 \\
\hline$[0,0,1,0,1,0]$ & 4.9805 & 7.2454 & 33.9235 & 33.3450 & 10.4812 & 10.2241 & 0.2520 & 0.2337 \\
\hline$[0,0,0,1,0,0]$ & 5.0917 & 2.7739 & 34.3792 & 33.7795 & 10.6518 & 10.3746 & 0.0401 & 0.0484 \\
\hline$[1,0,0,0,0,0]$ & 5.2129 & 0.2450 & 46.8940 & 45.5622 & 10.9709 & 10.6463 & 14.2778 & 11.9679 \\
\hline$[0,1,1,0,1,0]$ & 5.4474 & 4.1740 & 34.2954 & 33.6988 & 10.9919 & 10.6974 & 0.7858 & 0.8910 \\
\hline$[0,1,0,1,0,0]$ & 5.5586 & 1.1201 & 34.7075 & 34.0914 & 11.1672 & 10.8509 & 1.0646 & 0.9269 \\
\hline$[0,0,1,1,0,0]$ & 5.5902 & 5.1628 & 34.4179 & 33.8169 & 11.1491 & 10.8427 & 0.1431 & 0.1679 \\
\hline$[1,1,0,0,0,0]$ & 5.6799 & 0.0875 & 47.4014 & 46.0409 & 11.4798 & 11.1192 & 1.2668 & 1.0921 \\
\hline$[1,0,1,0,0,0]$ & 5.7114 & 1.5051 & 46.9130 & 45.5788 & 11.4709 & 11.1167 & 0.1570 & 0.1829 \\
\hline$[0,1,1,1,0,0]$ & 6.0571 & 2.8176 & 34.7170 & 34.1007 & 11.6641 & 11.3187 & 0.1208 & 0.1197 \\
\hline$[1,1,1,0,0,0]$ & 6.1783 & 0.3150 & 47.3865 & 46.0251 & 11.9796 & 11.5895 & 0.0440 & 0.0545 \\
\hline$[0,0,0,1,1,0]$ & 6.4746 & 2.6689 & 34.3569 & 33.7527 & 12.0510 & 11.6897 & 16.5757 & 19.1858 \\
\hline$[1,0,0,0,1,0]$ & 6.5958 & 0.2275 & 46.8482 & 45.5145 & 12.3604 & 11.9540 & 0.7195 & 1.0225 \\
\hline$[0,1,0,1,1,0]$ & 6.9415 & 1.5926 & 34.6966 & 34.0748 & 12.5682 & 12.1678 & 1.2792 & 1.4759 \\
\hline$[0,0,1,1,1,0]$ & 6.9730 & 5.6965 & 34.3964 & 33.7908 & 12.5475 & 12.1573 & 0.1441 & 0.1962 \\
\hline$[0,0,0,0,0,1]$ & 7.0009 & 0.1050 & 52.0818 & 50.3491 & 13.4421 & 12.9084 & 1.5090 & 1.7322 \\
\hline$[1,1,0,0,1,0]$ & 7.0627 & 0.1663 & 47.3710 & 46.0073 & 12.8703 & 12.4279 & 0.1559 & 0.2125 \\
\hline$[1,0,1,0,1,0]$ & 7.0942 & 2.0039 & 46.8676 & 45.5315 & 12.8599 & 12.4241 & 0.1579 & 0.1882 \\
\hline$[1,0,0,1,0,0]$ & 7.2054 & 0.1138 & 47.5753 & 46.2025 & 13.0277 & 12.5739 & 0.0486 & 0.0641 \\
\hline$[0,1,1,1,1,0]$ & 7.4399 & 4.0340 & 34.7068 & 34.0849 & 13.0644 & 12.6350 & 7.4653 & 8.8418 \\
\hline$[0,1,0,0,0,1]$ & 7.4678 & 0.1838 & 52.4400 & 50.6829 & 14.0018 & 13.4268 & 0.7117 & 1.0156 \\
\hline$[0,0,1,0,0,1]$ & 7.4993 & 0.7088 & 52.0526 & 50.3226 & 13.9299 & 13.3686 & 0.5989 & 0.7082 \\
\hline$[1,1,1,0,1,0]$ & 7.5611 & 1.0151 & 47.3563 & 45.9920 & 13.3697 & 12.8979 & 0.1546 & 0.2107 \\
\hline$[1,1,0,1,0,0]$ & 7.6723 & 0.0350 & 47.9744 & 46.5770 & 13.5407 & 13.0497 & 0.7052 & 0.8298 \\
\hline
\end{tabular}


Table 6: Equilibrium Solution (continued)

\begin{tabular}{|c|c|c|c|c|c|c|c|c|}
\hline "0,0] & 7.7038 & 38 & 47 & 46. & 13.5269 & 437 & 0. & 21 \\
\hline$, 1,1,0,0,1]$ & 9662 & 275 & & & & 3.8863 & .0783 & .0956 \\
\hline$[1,1,1,1,0,0]$ & 07 & & 47.9 & & & 2 & 536 & 710 \\
\hline$[0$, & 37 & 700 & 5 & 50 & 14.8749 & 4 & 7 & 0713 \\
\hline 01 & $88 ?$ & & & & 4.4201 & & & 3582 \\
\hline$[0,1,0,0,1,1]$ & 8506 & 3 & 52.5352 & 50.7627 & 5.4375 & 4.7746 & .0756 & .0806 \\
\hline$[0,0,1,0,1,1]$ & 8821 & 4375 & 52.1 & & & 28 & & 0.0005 \\
\hline & & & & & & & & 016 \\
\hline $1,1,0]$ & 1 & 100 & 729 & 4 & 46 & 15 & 36 & 0772 \\
\hline$[1,0,1,1,1,0]$ & 6 & 6 & 47. & 46. & 4.9189 & 36 & 888 & .0098 \\
\hline$[1,0,0$ & 46 & & & 6 & & 6 & 19 & 191 \\
\hline & & & & & & & & \\
\hline & 9.4603 & & 52.8 & & & & & \\
\hline$[0,0$, & 918 & & 52. & 56 & 57 & 27 & 970 & .1043 \\
\hline$[1,1,1,1,1,0]$ & & & & & & & & \\
\hline & & & & & & & & 19 \\
\hline$[1,0$, & 30 & 50 & 780 & 82 & 16.5365 & 15.7801 & 551 & 0.2178 \\
\hline$[0,1$, & 87 & & J/ & 90 & 15 & 72 & 12 & 28 \\
\hline ,1] & & & & & & & & 58 \\
\hline & & & & & & & & \\
\hline$[1,0,($ & 974 & 38 & 37 & 44 & 79 & 548 & 57 & 1.0742 \\
\hline$[0,1$, & 31 & & & & 78 & 0 & & 576 \\
\hline & & & & & 341 & 0 & & \\
\hline & & & & & & & & 973 \\
\hline$[1,0$ & & & 50 & & 77 & 64 & 53 & 2514 \\
\hline 0,1$]$ & 070 & 53 & 0.0000 & 00 & 54 & 16.5192 & 153 & .0202 \\
\hline & & & & & & & & \\
\hline$[1,1,1,0,1,1]$ & 27 & & & & 21 & 32 & 466 & .6493 \\
\hline$[1,1,0,1,0,1]$ & 99 & 3 & 5 & 5 & 16 & 14 & 23 & .0223 \\
\hline$[1,0,1,1,0,1]$ & 6054 & & 0 & 39 & 18.6824 & 17.7919 & 04 & 0.2004 \\
\hline & & & & & & & 24 & .6130 \\
\hline & & & 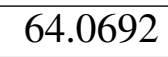 & & 19.6239 & 8.6758 & 91 & .2515 \\
\hline & & & & & & 19.1988 & 0.4979 & 0.7079 \\
\hline & 9882 & & & & & & 0.0199 & 0.0265 \\
\hline$[1,1,1,1,1,1]$ & 13.4552 & 1.5401 & 63.8076 & 61.5259 & 20.6711 & 19.6573 & 0.1407 & 0.1933 \\
\hline
\end{tabular}

